\title{
Qual a diferença entre o cérebro delas e o deles
}

\author{
Dr. Fabiano de Abreu Agrela Rodrigues ${ }^{1}$ \\ deabreu.fabiano@gmail.com
}

\section{RESUMO}

A discussão de quem é mais inteligente, se o homem ou a mulher, já não cabe mais nos dias de hoje. Por mais que a sociedade busque motivos para tentar comparar, seja para uma tentativa real de igualdade ou para um aproveitamento de uma possível desigualdade como argumento. Já é claro que as profissões estão de acordo com as facilitações intelectuais assim como desenvolvimento e adaptação para inclusão. Este artigo etermina as diferenças cerebrais de ambos os sexos para uma conclusão definitiva ao final.

Palavras-chave: diferença cerebros; cérebro masculino e feminino; diferença de gêneros.

\footnotetext{
${ }^{1}$ Doutor e Mestre em Ciências da Saúde nas áreas de Neurociências e Psicologia; Doutor e Mestre em Psicologia da Saúde; Neurocientista com especialização em propriedade elétrica dos neurônios, inteligência artificial, aprendizagem infantil, psicologia positiva, neurolinguística; especialização em nutrição clínica, pós graduações em neuropsicologia, antropologia, psicologia existencial; filósofo e jornalista.

Integrante da SPN - Sociedade Portuguesa de Neurociências - 814, da SBNEC - Sociedade Brasileira de Neurociências e Comportamento - 6028488 e da FENS - Federation of European Neuroscience Societies - PT30079
} 
Qual a diferença entre o cérebro...

\title{
What is the difference between their brain and theirs
}

\begin{abstract}
The discussion of who is more intelligent, whether the man or the woman, no longer fits nowadays. As much as society seeks reasons to try to compare, either for a real attempt of equality or to take advantage of possible inequality as an argument. It is already clear that the professions are in accordance with intellectual facilitations as well as development and adaptation for inclusion. This article determines the brain differences of both sexes for a definitive conclusion at the end.
\end{abstract}

Keywords: brains difference, male and female brain, gender difference

Artículo recibido: 02 enero 2022 Aceptado para publicación: 28 enero 2022 Correspondencia: deabreu.fabiano@gmail.com Conflictos de Interés: Ninguna que declarar 


\section{INTRODUÇÃO}

Os hormônios foram responsáveis por um domínio masculino em quase todo período evolutivo humano, mas a evolução do hormônio também está relacionada ao processo evolutivo assim como nosso cérebro. De acordo com a evolução e desenvolvimento intelectual finalmente estamos chegando a uma nova transformação, onde ambas inteligências se integram para uma nova evolução cujo resultado apenas supomos, mas mediante a nossa lógica atual, num córtex pré-frontal mais bem desenvolvido, podemos dizer que é necessária. O mais forte se determinou na evolução, mas a definição de forte em músculos não define o forte no emocional, como não define o mantenimento da espécie. Nossa sobrevivência é um resultado desta "parceria" homem e mulher e nos “encaixes" da inteligência e personalidade e assim vamos nos moldando de acordo com essa evolução e seu tempo.

As diferenças nos cérebros e na produção de hormônios determinam as distinções comportamentais assim como hábitos, personalidades e funções de cada gênero na sociedade. A plasticidade cerebral e as nuances relacionadas as variações na condição intelectual e produção hormonal deixa a caracterização dessas diferenças dos gêneros de acordo com o indivíduo, diluindo assim a diferença e determinando-a de forma singular independente do gênero.

\section{DIFERENÇA DOS CÉREBROS}

A questão de quem é mais inteligente, se o homem ou a mulher é imensamente colocada. Contudo, devemos antes perguntar quais as diferenças ao nível cerebral entre um e outros, pois essas são reais.

Começando pelos padrões de conexões entre os neurônios é diferente entre os dois géneros sendo que os homens têm cerca de $30 \%$ mais conexões entre os neurônios.

Certas funções cognitivas diferem entre homens e mulheres, embora a substratos anatómicos e funcionais subjacentes a estas diferenças permanecem desconhecidos. Porque a atividade neocortical está diretamente relacionada com funções cerebrais mais elevadas, numerosos estudos têm-se centrado no córtex cerebral na procura de possíveis correlatos estruturais de diferenças cognitivas de género. No entanto, não há estudos sobre possíveis diferenças de género a nível sináptico. No presente trabalho que utilizámos luz estereológica e 
correlativa e eletrão microscopia para mostrar que os homens têm uma sináptica significativamente mais elevada densidade do que as mulheres em todas as camadas corticais do neocórtex temporal. Estas diferenças podem representar um substrato microanatómico contribuir para as diferenças funcionais de género na atividade cerebral.

(DeFELIPE et all, 2009)

Por outro lado, cérebro das mulheres é menor do que dos homens, cerca de $12 \%$, mas isso não define a inteligência como um todo. O fluxo sanguíneo e a proporção de substância cinzenta das mulheres são mais avantajados.

A diferença mais óbvia entre os cérebros de homens e mulheres é o tamanho total - os cérebros dos homens são, em média, entre 10 e 15 por cento maiores do que os das mulheres. Num estudo recente, os neurocientistas compararam os cérebros de 42 homens e 58 mulheres postmortem, e descobriram que o dos homens pesava em média 1,378g (3lb), comparado com 1,248g (2,75lb) para as mulheres. Estas diferenças de tamanho têm sido encontradas repetidamente, mas só surgem quando se compara um grande número de pessoas, pelo que alguns cérebros de mulheres são maiores do que a média, enquanto que alguns de homens são mais pequenos. Estas diferenças refletem em parte o facto de os homens serem geralmente maiores e mais altos do que as mulheres, mas não estão relacionadas com diferenças de inteligência.

Os cérebros dos homens e das mulheres também diferem na composição geral. Os cérebros masculinos tendem a ter uma proporção ligeiramente superior de matéria branca, enquanto os das mulheres têm uma proporção mais elevada de matéria cinzenta na maioria das partes do córtex cerebral. Consequentemente, o córtex é ligeiramente mais espesso no cérebro feminino do que no masculino e, de acordo com vários estudos, é também ligeiramente mais convoluto. Existem também diferenças de sexo no tamanho das estruturas cerebrais individuais. O hipocampo, uma estrutura envolvida na 
formação da memória, é em média maior nas mulheres, a amígdala, que também está envolvida na memória, assim como as emoções é maior nos homens.

(COSTANDI, 2013)

Outra diferença a considerar é que as mulheres têm maior densidade de neurônios nas regiões relacionadas à linguagem enquanto que os homens está maior densidade verificase na região da lógica e espacial. Quando a mulher fala, os dois lados do lobo frontal são ativados, já no homem apenas o lado esquerdo.

O substrato cerebral das diferenças sexuais na cognição não é conhecido. Foi feita a hipótese de que as funções da linguagem são representadas mais bilateralmente no cérebro feminino do que no masculino). As mulheres podem assim usar ambos os hemisférios para funções da linguagem, enquanto os homens usam predominantemente o hemisfério esquerdo. Pensa-se que um padrão mais bilateral de representação linguística resultaria em melhores habilidades verbais, enquanto que o processamento viso-espacial seria inferior em assuntos com representação linguística bilateral. Assim, o défice feminino em termos de desempenho espacial é hipotético como resultado da competição entre funções verbais e espaciais no hemisfério direito. A teoria de que as diferenças sexuais na cognição resultam de uma representação mais bilateral das funções linguísticas nas fêmeas do que nos machos é apoiada por duas descobertas. Em primeiro lugar, foi relatado que os doentes com AVC do sexo feminino exibem uma deficiência verbal menos frequentemente após lesões do hemisfério esquerdo do que os doentes do sexo masculino. Em segundo lugar, estudos de ressonância magnética estrutural demonstraram que a assimetria do planum temporale (a superfície superior do lobo temporal sobrepõe-se em grande parte à área de Wernicke) é menos pronunciada nas mulheres do que nos homens.

No entanto, ambas as observações fornecem apenas apoio indireto para uma lateralização funcional reduzida no cérebro feminino. Presentemente, técnicas de imagem funcional tornaram-se disponíveis 
que podem visualizar diretamente a representação da linguagem cortical no cérebro humano. Vários grupos de imagens funcionais têm relatado dados sobre diferenças sexuais na representação da linguagem cortical, mas os resultados são inconsistentes. A fim de testar se a representação da linguagem é de facto mais bilateral no cérebro feminino do que no masculino, foi realizada uma meta-análise em estudos que avaliaram a atividade da linguagem com técnicas de imagiologia funcional em homens e mulheres saudáveis.

(SOMMER et all, 2004)

Mas as diferenças não se ficam por aqui. Podemos ainda observar que o hipocampo (região relacionada a memória) das mulheres é maior do que dos homens, já a amígdala (reguladora das emoções e memórias relacionadas a emoção, comportamentos sociais e excitação sexual) é menor, cerca de $10 \%$.

Mas nenhum estudo define que o tamanho da amígdala está relacionado ao homem ser mais agressivo e impulsivo, estando mais relacionado ao hormônio, no caso do homem a testosterona. Na mulher o estrógeno a faz mais delicada. Mas essas condições comportamentais também estão relacionadas com quantidade de testosterona recebida no útero, por parte da mulher.

É ainda observado que o sexo feminino possuí um sistema mais robusto nos neurotransmissores serotonina, dopamina e GABA, com maior concentração no sangue como é o caso da serotonina, quando deprimidas, menor concentração, por isso a prevalência de depressão e transtornos alimentares no sexo feminino.

A principal diferença entre os dois géneros é o cromossomo Y, que afeta a anatomia e comportamento. Também o hormônio define bastante essa diferença.

Em geral, as regiões do cérebro que diferem em tamanho entre homens e mulheres (como a amígdala e o hipocampo) tendem a conter concentrações especialmente elevadas de recetores para as hormonas sexuais.

Outra variável chave na composição de homens versus mulheres deriva dos cromossomas sexuais, que formam um dos 23 pares de cromossomas humanos em cada célula. Geralmente, as fêmeas têm dois cromossomas $X$ no seu par, enquanto os machos têm um 
cromossoma X e um Y. Um gene no cromossoma Y é responsável pela cascata de eventos de desenvolvimento que fazem com que corpos e cérebros assumam características masculinas. Alguns outros genes do cromossoma $Y$ podem estar envolvidos na fisiologia e cognição do cérebro. Os cientistas reconhecem rotineiramente que a presença ou ausência de um único par de base de ADN pode fazer uma diferença importante do ponto de vista médico. E quanto a um cromossoma inteiro? Enquanto os genes hospedados no cromossoma $X$ e no cromossoma $Y$ (cerca de 1.500 no $X, 27$ no Y) podem ter tido contrapartes no outro, este é agora o caso de apenas alguns deles. Cada célula do corpo de um homem (incluindo o seu cérebro) tem um conjunto ligeiramente diferente de genes de cromossomas sexuais funcionais dos que operam no corpo de uma mulher.

As diferenças baseadas no sexo na estrutura e fisiologia do cérebro refletem a alquimia destas interações hormona/recetor, os seus efeitos dentro das células, e a influência intermediadora das variáveis genéticas - particularmente a posse de um XX versus um genótipo XY. (GOLDMAN, 2017)

Embora, quem é mais inteligente, é a pergunta que todos fazem, não o podemos responder dessa forma tão leviana e pragmática. Não há o mais inteligente até porque QI varia de cada indivíduo, você pode ter uma mulher com o QI lógico maior que de um homem, mesmo quando, normalmente os homens possuem a região da lógica melhor desenvolvida. As mulheres têm conexões mais abundantes entre os dois hemisférios cerebrais, direito e esquerdo, e os homens têm melhores conexões dentro de cada hemisfério.

Numerosos estudos mostram diferenças subtis no comportamento masculino e feminino e também nas funções cognitivas. Os homens tendem a ser mais agressivos e a superar as mulheres em tarefas mentais que envolvem habilidades espaciais como a rotação mental, enquanto que as mulheres tendem a ser mais empáticas e a desempenhar melhor as tarefas de memória verbal e linguagem. Descobertas como estas são frequentemente exageradas para reforçar 
os estereótipos de que as mulheres são más no estacionamento ao contrário e que adoram conversar!

Em alguns casos, estudos individuais que pretendem mostrar diferenças sexuais em certas tarefas são desviados. Por exemplo, de acordo com um pequeno estudo post-mortem publicado em 1982, o corpus callosum, o enorme feixe de fibras nervosas que liga os dois hemisférios cerebrais, é proporcionalmente maior nas mulheres do que nos homens. Isto foi amplamente divulgado para significar que as mulheres são melhores em multitarefas, embora o trabalho subsequente tenha falhado em replicar os resultados. Um estudo mais recente mostrou que as mulheres são marginalmente melhores do que os homens a prestar atenção aos sons apresentados a ambos os ouvidos simultaneamente - isto foi interpretado por alguns como prova de que "os homens não ouvem".

Muitas destas afirmações são acompanhadas pela afirmação de que as diferenças observadas entre os cérebros dos homens e das mulheres são "hard-wired" e, portanto, irreversíveis. Sabemos agora, no entanto, que a estrutura cerebral e a função mudam em resposta à experiência, pelo que quaisquer diferenças observadas entre os cérebros de homens e mulheres poderiam também ser devidas a diferenças na educação e socialização. Até à data, porém, muito pouca investigação tem sido feita para investigar como diferentes estilos de nutrição podem influenciar o desenvolvimento do cérebro.

(COSTANDI, 2013)

Podemos dizer que o homem tem a região da lógica mais bem desenvolvida e a mulher tem um melhor desenvolvimento cognitivo. Ambos estão relacionados à inteligência. Eles têm a perceção do todo e elas são melhores em observar os detalhes.

\section{CONCLUSÃO}

Há diferenças nos cérebros masculino e feminino, mas elas não determinam quem é mais inteligente e sim que há distintos tipos de inteligências relacionados. A questão a ser levada em consideração não é a igualdade em si mas a necessidade da união de ambos para o desenvolvimento humano. Similares mas distintos, homens e mulheres dependem 
um do outro e, ambos, juntos, foram responsáveis pelo nosso desenvolvimento e sobrevivência. Há profissões em que, a facilitação intelectual determina o gênero, mas como seres adaptáveis e mediante à plasticidade cerebral, é possível o desenvolvimento de inteligências que encaixam ambos em profissões que, hoje, seriam relacionados às gêneros opostos.

Os hormônios são mais determinantes do que o cérebro para o comportamento e personalidade de ambos os gêneros, eles são responsáveis para que essa diferença seja mais determinante do que o próprio cérebro já que, o cérebro pode ser condicionado à nuances que determinam e moldam a capacidade intelectual.

\section{REFERENCIAS BIBLIOGRAFICAS}

Bruce Goldman. 2017. Two minds, The cognitive differences between men and women.

Consultado em 2021. Disponível em https://stanmed.stanford.edu/2017spring/how-mens-and-womens-brains-aredifferent.html

C. Moheb. 2013. 50 Human Brain Ideas You Really Need to Know (50 Ideas You Really Need to Know series) Quercus Editions, lda

Iris E. C. Sommer, André Aleman, Anke Bouma, René S. Kahn.2004. Do women really have more bilateral language representation than men? A meta-analysis of functional imaging studies Brain, Volume 127, Issue 8, August 2004, Pages 1845-1852, https://doi.org/10.1093/brain/awh207

L. Alonso-Nanclares, J. Gonzalez-Soriano, J. R. Rodriguez, and J. DeFelipe. 2008. Gender differences in human cortical synaptic density. Instituto Cajal, Consejo Superior de Investigaciones Cientificas, Avda Doctor Arce, 37, 28002 Madrid, Spain; and Department of Anatomy and Compared Pathological Anatomy, Veterinary Faculty, Universidad Complutense of Madrid, 28040 Madrid, Spain Edited by Edward G. Jones, University of California, Davis, CA, and approved July 24, 2008 (received for review April 15, 2008). 